\title{
Regress, unity, facts, and propositions
}

\author{
Matti Eklund $^{1}(\mathbb{D}$
}

Received: 28 October 2015 / Accepted: 1 July 2016 / Published online: 26 July 2016 (C) The Author(s) 2016. This article is published with open access at Springerlink.com

\begin{abstract}
The problem, or cluster of problems, of the unity of the proposition, along with the cluster of problems that tend to go under the name of Bradley's regress, has recently again become a going concern for philosophers, after having for some time been regarded as primarily of historical interest. In this paper, I distinguish between the different problems that tend to be brought up under the heading of the unity of the proposition, and between different related regress arguments. I present my favored solutions to these problems.
\end{abstract}

\section{Introduction}

The problem, or cluster of problems, of the unity of the proposition, and the cluster of problems that tend to go under the name of Bradley's regress, have recently again become a going concern for philosophers, after having for some time apparently been regarded as primarily of historical interest. ${ }^{1}$ I here present and defend my preferred resolutions of these problems.

The problem of the unity of the proposition is often brought up in conjunction with Bradley's regress, and the two problems are regarded as tightly historically connected. ${ }^{2}$ For example, Leonard Linsky begins his influential discussion of the problem of the unity of the proposition by stating a version of Bradley's regress and saying, "Russell's

1 See e.g. Burge (2007), Candlish (2007), Collins (2011), Davidson (2005), Gaskin (2008), Hanks (2015), King (e.g., 2007, 2009, 2013), Liebesman (2015), and Soames (e.g., 2010, 2014). However, as we will see, these authors focus on somewhat different problems; for example, some of these discussions are more linguistically oriented.

2 Bradley (1893).

$\bowtie \quad$ Matti Eklund

matti.eklund@filosofi.uu.se

1 Department of Philosophy, Uppsala University, Uppsala, Sweden 
concern with the problem of unity is a response to Bradley". ${ }^{3}$ I will start by (in sections two and three) discussing Bradley's regress, or rather to the family of problems associated with that label; as we shall see, there are crucial distinctions to be drawn. In section four, I relate to the issue of propositions. In sections five through seven, I introduce the problem of the unity of the proposition, properly so called-a problem that famously arises for prominent conceptions of propositions as structured entities. In section eight, I apply the lessons of the discussion of Bradley's regress to the relevant problems regarding the unity of the proposition. Section nine relates to Russell's aims when discussing these problems. Section ten wraps things up.

\section{Regress problems}

In spite of how familiar Bradley's regress is, and how simple, in some sense, the problem is, there is no truly canonical formulation of Bradley's regress in the literature. Bradley's own formulations are not very lucid and they also rely on his own somewhat idiosyncratic concerns; and there is no formulation in the secondary literature that is of canonical status. Let me zoom in on the problem that I want to focus on by presenting a number of different regress arguments and explaining why I choose to focus on the one I focus on.

Consider first the following regress: (1) Assume that it is a fact that a is F. (2) then a and $F$ are related by some relation, R. (3) Then it is a fact that a and F stand in R. (4) Then a, F and $\mathrm{R}$ are related by some relation $\mathrm{R}^{\prime}$. (4) Then it is a fact that $\mathrm{a}, \mathrm{F}$, and $\mathrm{R}$ stand in $R^{\prime}$. (5) Then a, F, R and $R^{\prime}$ are related by some relation $R^{\prime \prime}$. Etc. Assuming that the facts mentioned in (2), (4), (6), etc., are distinct—which they at first sight would appear to be, having different constituents, the upshot is that from the assumption that there is the one fact, that a is F, it follows that there are infinitely many different facts. I have stated the regress in terms of facts, but with some modifications one could use this kind of argument to conclude that there are infinitely many relations.

The main thing to note about this regress-call it the infinity regress - is that as it stands there is nothing obviously vicious about it. The conclusion is by no means clearly unacceptable. All we have is an argument to the effect that there are infinitely different entities - infinitely many different facts. There are, to be sure, parsimony considerations which would lead some to be loath to accept such a conclusion; but that is different.

One way to turn the infinity regress into a regress that is genuinely vicious would involve making assumptions to the effect that for each element in the endless series of relations or facts, it is explained by, or metaphysically dependent on, a later element. E.g., the fact that a is $\mathrm{F}$ would be dependent on the fact that a and $\mathrm{F}$ stand in $\mathrm{R}$, which in turn would be dependent on the fact that a, F and $\mathrm{R}$ stand in $\mathrm{R}^{\prime}$, etc. This regress - call it the dependence regress - is vicious, if we make the natural assumption that a chain of dependence must somewhere reach ground. Even given such an assumption, however, there are natural ways to block this dependence regress. Why, given that there are two

\footnotetext{
${ }^{3}$ Linsky (1992, p. 247). Gaskin (1995, p. 162), says that the problem of the unity of the proposition is what underlies Bradley's regress. Compare too Gaskin (2008, p. 345)
} 
facts like our facts that $\mathrm{a}$ is $\mathrm{F}$ and that a and $\mathrm{F}$ stand in $\mathrm{R}$, should it be said that the former depends on the latter? There are reasons for doubt. Even supposing that out of two necessarily coobtaining facts one can asymmetrically depend on the other, what could possibly underlie a claim to the effect that the less complex fact must depend on the more complex one, especially since such a claim leads to regress?

I have argued that the infinity regress is not vicious, and that what gets the dependence regress going is an assumption that is eminently deniable. But of course many theorists are preoccupied by the regress worry. It may seem as if I dismiss their concerns out of hand. But what I do think is that there is a regress argument in the vicinity more worth worrying about, and once we distinguish the infinity and dependence regresses from that argument, we see more clearly that those two regresses are not reasonable objects for philosophical concern.

Here is the more significant regress argument. Take a supposed fact: that a is (contingently ${ }^{4}$ ) F. What is the nature of this fact? If we think that the predicate stands for a property, the property $\mathrm{F}$, then arguably a and this property are constituents of the fact. But, the regress argument goes, the fact cannot simply consist of a and F. For a can exist and $\mathrm{F}$ can exist even if a is not F. For it to be a fact that a is F, a must instantiate F. But adding the talk of instantiation just gets us another constituent of the fact: the relation of instantiation, call it $\mathrm{R}$. But a can exist, $\mathrm{F}$ can exist, and $\mathrm{R}$ can exist even if a is not F. Trying the same strategy as before we can say that a, F and R must stand in the right relation for it to be a fact that a is F. But it should be clear that we are off on a regress. Let us call this the constitution regress.

As stated, this regress concerns facts. But we hardly need to reify facts to get the regress going. All we need is a notion of something's being the case, whether or not this is to be thought of in terms of entities such as facts: Suppose that a is - contingentlyF. What does the world need to be like in order for it to be so? The existence of a and $\mathrm{F}$ is not sufficient for a to be F. For a to be F, a must instantiate F. But the existence of a, F, and R is not sufficient for a to be F. Etc. Facts can seem to be mysterious entities, and it may be attractive to take the regress as an argument against the existence of such entities. But since the problem arises independently of the postulation of facts, such a response does not go to the heart of the problem.

The regress displayed by this argument brought up clearly is vicious, so some way of blocking the argument must be found. At no stage of the reasoning do we actually find ourselves in a position to say that the fact exists - or that something is the casebut we just add more and more entities, to no avail. Here the problem doesn't concern the existence of infinitely many relations or facts; nor is it a matter of dependence relations between facts. It rather concerns what it takes for one fact to obtain in the first place. ${ }^{5}$ One might put it as follows: whereas the dependence regress is about what

\footnotetext{
4 The restriction to contingent property instantiation is in principle eliminable. But it makes the discussion more straightforward.

5 I am not the first one to single out this problem for special attention. See here also e.g. MacBride (2005), p. 86f, as well as Orilia (2007), who both take care to distinguish this kind of regress argument from others. Since this argument concerns what it takes for a fact to obtain in the first place, a theory like Orilia's fact infinitism, which accepts an infinity of ever more complex facts, each dependent on a more complex one, does not help. For the same reason, Gaskin (2008) heroic stance with respect to the dependence regress, saying that it is benign and explanatory, is simply out of place here. Gaskin (2008) is not always clear on
} 
other facts a given fact is dependent on, the constitution regress problematizes how a fact is constituted to begin with.

The difference between the constitution regress and the dependence regress is well illustrated by the fact that what would be potentially promising ways of dealing with the dependence regress and non-starters when it comes to the constitution regress. Consider the suggestion-associated with David Armstrong - that the infinite series of facts considered in the infinity regress and the dependence regress can be collapsed: all the supposedly different facts are actually identical. The fact of R's holding between a and F is identical to $\mathrm{R}^{\prime}$ 's holding between a, R and F, etc. Setting aside whether this idea is plausible, it speaks to the problem raised by the dependence regress, and promises to disarm it. There is not an infinite series of dependence relations on ever more complex facts, for the supposedly different facts are all one and the same. But the suggestion is completely powerless against the constitution regress. Saying that infinitely many supposedly different facts are actually identical does not answer the question of how a single fact is constituted in the first place. ${ }^{6}$

Suppose, as a further illustration, that one proposes to deal with the dependence regress by finding a way of accepting the idea of endless chains of dependence. That does not immediately help with the constitution regress, for this response to the dependence regress only speaks to how different facts relate to each other. It does not speak to the question of how individual facts are constituted in the first place. Even if, assuming there can be facts, facts may depend upon each other in never-ending chains of dependence, postulating such chains of dependence does not help when it comes to the very possibility of there being facts to begin with.

An illustration of failure to distinguish clearly between the infinity regress and the constitution regress might also be instructive. In a recent discussion of Bradley's views, Candlish (2007) introduces Bradley's regress as follows: if we hold that "relations are real", then relations "would be themselves extra terms which would require further relations in order to link them to the terms which they were supposed to be relating (and so on ad infinitum)". 7 He then goes on to describe Russell (1903/96) response that the regress is not vicious, and remarks "even if [Bradley's] argument does not prove a vicious infinite regress, it still threatens to show that the reality of relations requires an ontology embarrassing to anyone even as easy-going as the Russell of 1903". ${ }^{8}$ But later in the very same discussion, Candlish provides an analogy (with origins in

\footnotetext{
Footnote 5 continued

whether it is (a proposition analogue of) the dependence regress or (a proposition analogue of) the constitution regress that is being addressed. But when Gaskin summarizes his position, p. 356, he unquestionably speaks of an infinite series of propositions and must have something like the dependence regress in mind. For criticism of Gaskin, see Macbride (2014).

6 Armstrong (1989, p. 109f). The regress Armstrong has stated the most explicitly (p. 108) seems to be a version of what I have called the infinity regress, and his proposal is a relevant response to that. But he also states that the problem has to do with the fact that "in general...the fact that an object instantiates a certain property does not flow from the nature of the object and the nature of the universal that are involved", and that relates more directly to the constitution regress. Maurin (2012), p. 800, makes a point similar to that I am making in the main text.

7 Candlish (2007, p. 167f).

8 Candlish (2007, p. 169).
} 
Wittgenstein's Tractatus (1922)): "Suppose I am given the task of making a chain out of some loose metal rings, and when I come to join any two of them, I respond by asserting that we need a third ring to do the job, so that the most I can achieve is just the addition of more rings to the collection". 9 The Russellian response that Candlish mentions is a possible (and I think correct) reply to the infinity regress; the most that could be said against it is that it leads to an embarrassing ontology, as Candlish says. But the reply is completely beside the point as a reply to the constitution regress, and it is the constitution regress that is illustrated by the chain analogy. Even if I were to add infinitely many metal rings, I would not thereby manage to make a chain. Analogously, even adding infinitely many relations does not suffice to constitute a fact.

To my mind, the constitution regress is the most interesting of the regress arguments. But again there is a fairly straightforward resolution. Even before being presented with a regress argument, one might well have thought that for a fact to obtain, the mere existence of its constituents is not, in general, sufficient for it to obtain. It also matters what the constituents are like and how they are related to each other. The regress arises solely because it is assumed that a fact's obtaining is fully determined by existence of its constituents. Once we abandon this assumption, the problem goes away.

The diagnosis may become clearer if the reasoning underlying the constitution regress is laid out as follows: (1) Suppose that the fact that a is F obtains. (2) The existence of a and $\mathrm{F}$ is not sufficient for this fact to obtain. (3) For the fact to obtain, a and F must also be suitably related. (It is because this necessary condition is not necessarily met by the mere existence of a and $\mathrm{F}$ that the mere existence of a and $\mathrm{F}$ is not sufficient.) (4) So there must exist a relation-R-relating a and F. (5) This relation $\mathrm{R}$ contributes to the fact's obtaining exactly by being a constituent of it. (6) But the existence of a, F, and R is not sufficient for the fact to obtain. (7) For the fact to obtain, a, F, and R must also be suitably related. (8) So there must exist a relation$\mathrm{R}^{\prime}$ —relating a, F and R. (9) This relation, $\mathrm{R}^{\prime}$, must itself be a constituent of the fact. Etc.

What is said in (2) and (3) is unassailable. The believer in relations would seem to have no general reason to balk at (4). What follows (5) seems safe for the same reasons. But why, exactly, should (5) be accepted? When the reasoning is set out this way, (5) seems like an obvious culprit. In fact, (5) seems to go wrong in two ways. First, can we not say that even if, necessarily, the fact obtains only if its constituents stand in relation $\mathrm{R}$ to each other, and even if, in some sense, it is the constituents being thus related that what makes the fact what it is, $\mathrm{R}$ need not be a constituent of the fact? Compare perhaps: the constituents of a sentence do not include the relation which relates the constituents of a sentence into the sentence they are. So it is not well motivated that the relation that relates the constituents is itself a constituent. Or compare sets. The set membership relation is not a further constituent of a set, but the set's nature and existence is due to the set membership relation and what it is like. Let the constituency assumption be the assumption that the relation postulated in (4) would have to be a constituent of the facy itself. Then what I have just said is: the constituency assumption should be rejected. Second, of course this first point does not

${ }^{9}$ Candlish (2007, p. 170). 
do away with the regress. Even if we do not say that the new relation is a constituent of the fact, it still remains that the mere existence of this relation, together with the existence of the constituents, is not sufficient for the fact to obtain. There is still a regress looming: the existence of a and $\mathrm{F}$ is not sufficient for the fact to obtain; the existence of a, F and R is not sufficient for the fact to obtain; the existence of a, F, R, and $\mathrm{R}^{\prime}$ is not sufficient for the fact to obtain, etc. But to get around the regress one can denyexistentialism, the view that the existence of the constituents, and of the relation which relates the constituents, is in general sufficient for a fact to obtain. Then the main point regarding the constitution regress is that existentialism is false. But this, far from being a problem, is a result. What the world is like-what facts there are-is not determined solely by what particulars, properties and relations exist, but also by how these entities are related to each other. But the constitution regress does not get off the ground without the existentialist assumption.

Something like existentialism is assumed in the literature on truthmaking. What truthmaker theorists look for are entities whose very existence makes a true claim true. Without the existentialist assumption one could appeal not only to whether things are but how they are. This whether/how formulation echoes how David Lewis (1992) makes the point in a critical discussion of Armstrong, saying that true predications are true "not because of whether things are, but because of how they are". ${ }^{10}$ There is obviously significant resemblance between this and my proposed way of dealing with the constitution regress. But Lewis is concerned with truthmaker principles, which concern what facts or other entities make true propositions true. He criticizes Armstrong's view that every truth needs a truthmaker, an entity whose existence entails the truth in question. This is a different type of issue from that raised by the constitution regress. One can well accept what I insist on when it comes to what it takes for a fact to obtain, while holding on to the principle Armstrong maintains and Lewis rejects, thinking that for every true proposition there is a fact that makes it true. ${ }^{11}$

The present suggestion may be motivated by comparing the view of a nominalist who denies the existence of properties, relations and facts and takes only particulars to exist. She will still hold that it can be the case, e.g., that John loves Mary-and she as much as anyone else will have to hold that the mere existence of John and Mary is not sufficient for this to be so. What she will say is that John loves Mary only if John and Mary also are related in the right way, where she would add that the talk about their being related is not talk about any further entity, a relation. What I am saying is that also someone who believes in facts and relations can say something similar. If it is a fact that John loves Mary, then John, loving and Mary not only exist but are also related the right way, by instantiation. So there will be a fact with John, loving, Mary and the relation of instantiation as constituents. But this does not mean that the relation of instantiation will be a constituent of the fact that John loves Mary; nor does

\footnotetext{
10 Lewis (1992, p. 216).

11 In his (2002), Lewis does explicitly discuss Bradley's regress. But he does not propose a solution to a general problem. His aim is rather mainly negative: he argues that when an individual has a property, this is not to be metaphysically explained by appeal to a relation of having since that leads to regress. What he says is however fully consistent with what I say. He also makes the point that once we distinguish between the infinity regress and the dependence regress, the infinity regress can be seen to be non-vicious.
} 
it mean that the simpler fact is metaphysically explained by the more complex one. Generally, accepting that there are such entities as relations ought not to put one in a worse position than the nominalist when it comes to accounting for what it is for something to be the case. It would be odd otherwise. The believer in relations does not have fewer moves available than the nominalist does. She is in a worse position than the nominalist is in only if she provides a theory of what the existence of such entities as relations helps explain, such that this theory gives rise to a vicious regress of purported explanations. Merely accepting the existence of the entities the nominalist does not believe in does not lead to such problems.

Let me also revisit step (4) in the above reasoning. I said above that the believer in relation has no reason to balk at that. But there is more to be said. One kind of friend of relations postulates such entities as relations in order to explain every instance of relatedness. That theorist must postulate relations to account for each case of relatedness. But if the friend of relations does not postulate relations in order to explain relatedness, she can comfortably say that sometimes there is relatedness without there being some corresponding relation. ${ }^{12}$ It is then open to her to reject (4).

There is a way in which the present response is modest. When Bradley himself brought up the regress he did it to cast doubt on the possibility of relatednessof there being distinct entities standing in relations to each other-in the first place. There there is nothing in the above that serves to respond to someone who is resolutely skeptical about the possibility of relatedness. If Bradley were to respond "but you are simply helping yourself to the idea of different things being related!", I would have to plead guilty as charged. An existentialist who postulates the existence of relations to explain relations can be seen as trying to meet Bradley's challenge: relatedness is explained in terms of the existence of some things, and this can be seen as a kind of reductive explanation. One can of course doubt the success of the explanation, not only because it runs head-first into the constitution regress but also because the postulated entities, the relations, would have to be of such a special kind. Will not the theorist demanding a reductive account of relatedness balk at these supposed entities, even regress aside? The general point remains that the existentialist can be seen as trying to meet a demand to explain relatedness in terms of something less problematic whereas the present suggestion just skirts this demand.

Della Rocca (2013) has recently urged that Bradley is right in rejecting relations. When making the case for Bradley he is explicitly relying on an assumption to the effect that relatedness must be explained in some reductive fashion, and if it cannot be explained we should not agree that relatedness obtains if it cannot be thus explained. He thinks that Bradley's argument shows that the demand for an explanation cannot be met. My view is that Della Rocca is right about the possibility of meeting this demand for explanation, but that one shouldn't accede to this demand. The best the

\footnotetext{
12 Compare two different motivations for postulating properties: (a) to explain predication, and (b) to explain supposed similarities between it being the case (say) that the house is red and that the rose is red. If one postulates properties for reason (a) one will find it awkward to say that there can be predication even though there is no property to predicate. But if one postulates properties for reason (b), one can say that predicates only ascribe properties when they correspond to something genuinely similarity-making and not all predicates do so. Similarly for relations. (Compare Lewis 1983, p. 349ff.) One can postulate relations for a reason analogous to (b) as well as for a reason analogous to (a).
} 
friend of relatedness can do is to do the sort of thing I have done here, relying on a non-reductive account of relatedness. ${ }^{13}$

One suggested way of dealing with Bradley's regress that I so far have not brought up is the suggestion to posit relational tropes (contrast: relations as universals). While John, love and Mary can exist without John's loving Mary, it cannot be that John, Mary and the relation trope John's-love-for-Mary exist while John doesn't love Mary. ${ }^{14}$ Whatever the virtues of this way of going might otherwise be, I take it that this would not, and should not, convince a theorist making the same theoretical assumptions as Bradley and Della Rocca: this theorist will demand that the existence of relational tropes be sufficiently explained in turn, given as these entities have relationality baked into them.

\section{Lewis on Bradley's regress}

When discussing Bradley's regress in his (2002), Lewis says:

I would be willing enough to believe in a having relation that something bears to a property; or in a triadic having relation that an enduring thing (if such there be) bears to a property and a time; or in a relational property of, say, bearinghaving-to-bent-and- $t_{1}$.

But I do not think that these relations can explain having simpliciter. Having simpliciter is not a relation, whatever grammar may suggest. What is it, then? I don't know what more can be said. It is all very well to say that the copula 'non-relational tie' or that properties are 'unsaturated' and await completion by their bearers. These remarks at least have the merits of pointing away from the idea that having is relational. But they don't point toward much of anything. Bradley's regress shows that if we insist on trying to explain having simpliciter in terms of relational having, the explanation we seek will never be finished. ${ }^{15}$

The regress problem that Lewis goes on to describe is what one would expect: $\mathrm{X}$ has 1 $\mathrm{P}$ by having (having $_{1}, \mathrm{P}$ ), by having (having $_{2}$ having $_{1}, \mathrm{P}$ ), etc. Lewis's points about having are reminiscent of Armstrong's view that instantiation is not really a relation, and Lewis does also refer to Armstrong in connection with making his argument. ${ }^{16}$

Lewis says all this very authoritatively. But how could having simpliciter fail to be a relation? Suppose a is, contingently, F. Then the mere existence of a and F is not sufficient for it to be the case that a is F. What is more, a has to actually be F. Or, as one might also put it, a and $\mathrm{F}$ must also be related: a must have $\mathrm{F}$. But what then to

\footnotetext{
13 Della Rocca does not explicitly speak of relatedness per se but about "the reality of relations". It can sound as if he is just rejecting such entities as relations. But it is clear from the context that he casts his net wider and is concerned with the possibility of different things being related.

One way of dealing with Bradley's regress that I have not dealt with in the main text is the

14 See e.g. Maurin (2012).

15 Lewis (2002), p. 6.

16 See Lewis (2002, p. 6). Lewis refers to Armstrong (1978, pp. 106f); compare also e.g Armstrong (1989, p. 110).
} 
say about the regress that Lewis states-a regress which, in Lewis' words, rules out that having is a relation?

My favored view is that the fact that a is F has two constituents, a and F. They are related by a genuine relation, the having ("simpliciter") relation or the instantiation relation, but that relation is not thereby a constituent of the fact. There is another fact whose constituents are a, having and F, and that fact necessarily obtains exactly when the fact that a is F obtains, but that is a different fact. And it is wrong to say that the fact that a is F depends on the more complex fact.

Does what Lewis says cast any doubt on this picture-a picture on which, to stress, having simpliciter is a relation? I don't see that it does. No regress arises. Even if having (or having ${ }_{1}$ ) is a relation, and even if, necessarily, having 1 holds between $\mathrm{X}$ and $\mathrm{P}$ only if having 2 holds between $\mathrm{X}$, having ${ }_{1}$, and $\mathrm{P}$, etc., one just need not accept that it is by virtue of having 2 's holding between $\mathrm{X}$, having ${ }_{1}$ and $\mathrm{P}$ that $\mathrm{X}$ has $_{1} \mathrm{P}$. Believing that there is such-and-such a relation is one thing; believing it has an explanatory role of certain kind is quite another. It is the latter that leads to regress.

\section{Propositions}

Thus far I have been concerned with Bradley's regress, which concerns facts. Eventually I will relate what I have said to the unity problems afflicting theories of structured propositions. In this section I take the first steps, by discussing how problems analogous to the constitution regress affect propositions.

Assume the Russell (1903/96) view on propositions as entities with particulars, properties and relations as constituents-henceforth, the "Russellian" view on propositions. Then the nature of a proposition is not fully determined by what its constituents are. For example, two distinct propositions can be made up of the same constituents. (E.g., the proposition that John loves Mary and the proposition that Mary loves John.) More radically, the mere collection of things, John, loving and Mary, can be said not to amount to a proposition at all. To, so to speak, arrive at the proposition that John loves Mary, we need, it may be said, in addition to John, loving and Mary, a relation relating John, loving and Mary in the right way. (In this case a candidate might be something like the relation $x$ and $y$, in that order, are represented as instantiating $R$.) But the existence of John, Mary, loving, and this relation likewise do not uniquely determine this proposition. Etc.

The proposition regress, as we may call it, is not exactly parallel to the constitution regress. The existence of what we would ordinarily take to be the constituents of a structured proposition is metaphysically sufficient for the existence of the proposition: necessarily, if the constituents exist, so does the proposition. This differs from the case of facts. But to the extent that the proposed solution to the problem posed by the constitution regress is attractive, a parallel solution to the problem posed by the proposition regress should be attractive: the proposition is its constituents related in a particular way, and the relation which relates the constituents is not simply regarded as another constituent if the proposition. ${ }^{17}$

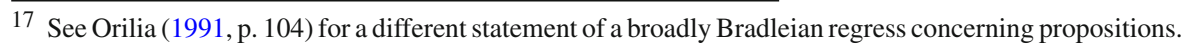


When discussing the issue that has become known as the problem of the unity of the proposition — and which I will focus on more directly below-Russell (1903/96) says:

Consider, for example, the proposition 'A differs from B'. The constituents of this proposition, if we analyze it, appear to be only A, difference, B. Yet the constituents, placed side by side, do not reconstitute the proposition. The difference which occurs in the proposition actually relates A and B, whereas the difference after analysis is a notion which has no connection with A and B. It may be said that we ought, in the analysis, to mention the relations which difference has to A and $\mathrm{B}$, relations which are expressed by is and from when we say 'A is different from $B$ '. These relations consist in the fact that $A$ is referent and $B$ relatum with respect to difference. But 'A, referent, difference, relatum, B' is still merely a list of terms, not a proposition. A proposition, in fact, is essentially a unity, and when analysis has destroyed the unity, no enumeration of constituents will restore the proposition. The verb, when used as a verb, embodies the unity of a proposition and is thus distinguishable from the verb considered as a term, though I do not know how to give a clear account of the precise nature of the distinction. ${ }^{18}$

This amounts to the proposition regress. Russell does not initially state his problem as a regress. But later on in this passage Russell states what amounts to the beginning of a regress, adding the further items "referent" and "relatum", but noting that adding these further items does not help.

Later in (1903/96), Russell explicitly relates to Bradley's regress:

Mr Bradley...has based an argument against the reality of relations upon the endless regress arising from the fact that a relation which relates two terms must be related to each of them. The endless regress may be undeniable, if relational propositions are taken to be ultimate, but it is very doubtful whether it forms any logical difficulty. We have already had occasion (\$55) to distinguish two kinds of regress, the one proceeding merely to perpetually new implied propositions, the other in the meaning of a proposition itself; of these two kinds, we agreed that the former, since the solution of the problem of infinity, has ceased to be objectionable, while the latter remains admissible. We have to inquire which kind of regress occurs in the present instance. It may be urged that it is part of the very meaning of a relational proposition that the relation involved should have to the terms the relation expressed in saying that it relates them, and that this is what makes the distinction, which we formerly (\$54) left unexplained, between a relating relation and a relation in itself...[W]e shall have to conclude that a relational proposition $\mathrm{aRb}$ does not include in its meaning any relation of a or $\mathrm{b}$ to $\mathrm{R}$, and that the endless regress, though undeniable, is logically quite harmless. ${ }^{19}$

\footnotetext{
18 Russell (1903/96, Section 54).

19 Russell (1903/96, Section 99).
} 
The way Russell presents his view on this in somewhat problematic, especially given the fact that he has earlier in the same discussion emphasized that propositions do not genuinely have meanings. ${ }^{20}$ Presumably what he is here talking about when talking about the "meaning of a proposition" is roughly how a proposition is constituted. His claim is then that the proposition $a R b$ contains only $a, R$ and $b$ as constituents even if there will be further relations obtaining between the constituents of this proposition. Russell distinguishes between on the one hand what he takes to be a clearly harmless regress merely implying the existence of infinitely many entities and on the other hand a potentially more significant one. Russell's discussion parallels the present one. What he sets aside as harmless corresponds to the infinity regress, whereas the regress he regards as more significant corresponds to the constitution regress (as it arises in the case of propositions).

Russell's own solution to the constitution regress as it arises in the case of propositions is mentioned toward the end of the first of the quoted passages. He says that there are two ways in which "verbs"- that is, relations-occur in propositions. They can occur as just another constituent or as a relation actually relating. Russell's suggested solution has come in for a lot of criticism, and I will turn to that later. For now let me just stress the similarity between a central element of what Russell proposes and I what I propose. It is an element of both suggestions that relations can play two different roles in regards to propositions. They can be further constituents, and they can play a role in another way- "actually relating". To me this seems very commonsensical. Compare a different case, sets. Take the set S: $\{$ love, hatred $\}$. The relations love and hatred are members of $S$. The set membership relation also plays a role in what $S$ is like, but of a fundamentally different kind. It serves for example to distinguish $\mathrm{S}$ from the mereological sum of love and hatred.

\section{The unity of the proposition}

Let me now, finally, turn the problem of the unity of the proposition. In fact, there are several different problems here, and they deserve distinguishing between. The problems most naturally come up against a background of the Russellian view on propositions, and I will first bring them up in that setting. The problems can also arise given other views on propositions, but the extent to which it is so is another matter. ${ }^{21}$ In this section I will only detail the different unity of the proposition problems. In section six I will briefly discuss and then set aside a related problem. In section seven I will compare some well-known attempts to deal with the unity problems, in part just to illustrate the problems themselves. In section eight I will present my own preferred view, which relates to what I have said about the constitution regress.

One reason it is important to distinguish the different problems is that it cannot be expected that all the problems should receive the same sort of solution. This will be a theme in my later discussion of these problems.

\footnotetext{
20 Russell (1903/96, Section 51).

21 The problems I distinguish between below are in the forefront in, e.g., recent discussions by Candlish (1996), Candlish (2007), Gaskin (2008), Hylton (1984) and Sainsbury (1996).
} 
First, we have

DIFFERENCE: Why is not the proposition that $\mathrm{p}$ identical to the fact that $\mathrm{p} ?^{22}$

The proposition that John loves Mary contains John, loves, and Mary as constituents, in that order. So does the fact that John loves Mary. Mustn't it then be the case that the proposition and the fact are identical? But that would be an embarrassment: it would then be impossible to judge a false proposition to be true. For a thinker to be able to judge a proposition to be true, the proposition must exist. But then the corresponding fact must exist. And it is sufficient for a proposition to be true that the corresponding fact exists. This was a famous problem with Russell (1903/96) view. It is obviously avoided by any view on which the constituents of the proposition that $\mathrm{p}$ are different from the constituents of the fact that $\mathrm{p}$, for example a view on which propositions consist of senses or of linguistic entities. However, even for such a view a problem of Generalized Difference arises: how is a given proposition p different from other complex entities with the same constituents as p? Second, there is

ORDER: How can the propositions that John loves Mary and that Mary loves John be different?

The propositions contain the same constituents. How can they still be different $?^{23}$ Third, we have

COMBINABILITY: Take the constituents of propositions: e.g. John, loves, Mary, etc.—on Russell's view, the worldly correlates of 'John', 'loves' and 'Mary', etc. Some of them can be conjoined so as to form propositions (e.g., John,loves, and Mary); some others cannot (e.g., John and Mary). Why? ${ }^{24}$

None of these first three problems is naturally called the problem of the unity of the proposition. The problem of unity, properly so called, rather seems to be a fourth distinct problem:

UNITY: How can there be this complex, the proposition, made up of its constituents, as opposed to merely (the collection of) the constituents themselves?

\footnotetext{
${ }^{22}$ See e.g. Candlish (1996, p. 105f), for a discussion of this in the context of discussing the unity of the proposition.

23 The problem of Order is for example emphasized in Candlish (1996) discussion of Russell's different ways of dealing with the problem of the unity of the proposition.

Using the label 'Order' suggests that the difference between the propositions is that the constituents are ordered differently. This can be seen as tendentious. See e.g. Fine (2000) and Williamson (1985), who focus on the problem for this assumption that arises if the proposition (or fact) that John loves Mary and the proposition (or fact) that Mary is loved by John are one and the same fact. Since such details are orthogonal to my main topic here, I will slide over them. Even if, strictly, it is false that the constituents of a proposition are ordered, the problem of Order arises so long as the proposition that John loves Mary and the proposition that Mary loves John are different propositions, and Fine and Williamson do not deny that.

${ }^{24}$ In a general discussion of Russell's attempts to deal with the problem of the unity of the proposition, Hylton (1984) raises the objection against Russell's multiple relation theory of judgment that the theory provides no explanation of "why I cannot form a judgment from any selection of objects with which I am acquainted, and so judge, for example, that table penholders the book" (p. 386f). The example is Wittgenstein's, and he credits the objection to Wittgenstein. The worry, as Hylton sees it, is that of Combinability.
} 
The problems of Difference, Order, Combinability and Unity, although raised as problems regarding propositions, have counterparts in the case of facts. In the case of Difference this is immediate. When it comes to Order one can ask: what is the difference between the fact that John loves Mary and the fact that Mary loves John? When it comes to Combinability one can ask: why can some collections of entities but not others combine so as to form a fact? When it comes to Unity one can ask: how can there be a complex entity, the fact, as opposed to merely the collection of the constituents of this entity?

What is more, problems similar to that of Unity arguably arise with respect to all complex entities; or, if one thinks 'mere' aggregates or collections are unproblematic, all complex entities which are not mere aggregates or collections. In each case one may ask: how can there be a complex entity here, as opposed to merely the constituents themselves? The problem is not specific to propositions.

There are some commonalities between the problems having to do with of the unity of the proposition and the problem posed by the constitution regress. In each case we have a certain complex entity whose existence can seem to be explained in terms of simpler entities. In each case it seems the mere existence of the simpler entities is not sufficient to explain the existence and nature of the complex entity, and that is seen as a problem.

\section{Representation}

Some philosophers-see for example Sainsbury (1996), Soames (e.g. 2010, 2014) and King (e.g. 2007, 2009, 2013)—prominently bring up another problem in connection with that of the unity of the proposition:

REPRESENTATION: How can there be such things as propositions, which have representational properties but are not themselves linguistic or mental or dependent on anything linguistic or mental (but are expressed by linguistic or mental things)?

This is an interesting and potentially deep problem. However, there is some reason for doubt concerning the extent to which it is connected with the other unity problems, and how reasonable it is to take this problem to be that which was discussed in early analytic philosophy. I do not see the problem of representationality as what Russell was concerned with. Moreover, the problem is quite different in kind from the other problems brought up in connection with the unity of the proposition. For example, the problem of Representation is not essentially bound up with the idea of propositions being structured entities built up from simpler parts. As Sainsbury (1996) stresses, friends of the view that propositions are sets of possible worlds face the embarrassment that mere sets of worlds do not seem to be the sort of thing that can be true or false. This is not to deny that there can be theoretical assumptions under which Representation is intimately connected with the problems brought up in the last section. ${ }^{25}$

\footnotetext{
25 For example, Candlish and Damnjanovic (2012) argue that for Wittgenstein, a proposition's capacity to represent is tied to its being a unity.
} 
In for example his (2014), Soames rejects Frege's and Russell's accounts of structured propositions on the ground that these accounts cannot explain how propositions can be representational. But first, it is in principle open to a friend of Frege or Russell to maintain that while her account does not properly explain the representationality of propositions, representationality is a primitive feature of propositions, not amenable to further explanation. Second, more specifically, for Frege, propositions (or what he called Thoughts) are not the only abstract intrinsically representational entities. Senses of individual expressions are also intrinsically representational. And Frege is no more able to explain their representationality than he is able to explain the representationality of propositions. So there is no problem specific to propositions there, and no problem specifically related to the complexity of propositions. Things do however stand differently for Russell in this regard, since typical Russellian propositions will have only non-representational constituents. Questions about the unity of Russellian propositions and questions about how these propositions can be representational may be linked, because Russellian propositions are representational unities built up from non-representational constitutents. Sometimes a certain problem concerning sentences is presented under the heading of the unity of the proposition: what explains the difference between a declarative sentence and a mere list? As Howard Peacock (2011) argues, no maneuvering dealing with the metaphysics of propositions could help with this problem, for whatever we say about propositions, the question of how linguistic items get to be linked to propositions remain.

Much recent work focusing on problems relating to propositions and unity, like Davidson (2005), Burge (2007) and Collins (2011) is in fact primarily linguistically oriented, asking how it comes about that a sentence manages to say something and not just be a mere list. Burge, as well as Wright (1998) and Liebesman (2015), argues that predicates are special: while predicates like singular terms have worldly correlates, predicates do not (simply) refer but they predicate, or ascribe. For our purposes it does not matter much what predication or ascription is: all that matters is that like reference it is a relation between expressions and worldly correlates but yet it is a relation different from reference. Predicates are in this way special. This is what accounts for the difference between a sentence which actually says something on the one hand and a mere list on the other. It may be natural to combine this view with a view on the metaphysics of propositions such as the one I have suggested. On the linguistic side, the contributions of the expressions that make up a sentence is not exhausted by what they stand for, and the nature of a sentence is not wholly determined by what the expressions stand for; on the metaphysical side, the nature of a proposition is not wholly determined by what its constituents stand for. But natural though the connection may be, it is not inevitable. Most radically, the friend of the ascription view on how predicates work can reject the very notion of propositions. Consistently with her view on sentences she can regard the problems regarding the metaphysics of propositions as insurmountable. Even if she does accept the existence of propositions she can find another view more congenial to what she holds about the sentences than what I have said about propositions. Thus, when Liebesman turns to the issue of the unity of the proposition, what he says is that the ascription relation "gives rise to propositions": "the fact that "wise' ascribes wisdom to Frege suffices for the existence 
of the proposition that Frege is wise". ${ }^{26}$ As Liebesman brings up, this on the face of it makes the existence of propositions contingent. He briefly discusses some ways to avoid this consequence. ${ }^{27}$ But the important point for present purposes is that nothing that I have claimed regarding the metaphysics of propositions in any way even suggests that the existence of propositions would be at all dependent upon a linguistic relation.

\section{On some purported solutions to the problem of unity}

To get a better grip on the different unity of the proposition problems and their relations, let us consider, and briefly evaluate, Fregean ideas that have been held to help with the problem of the unity of the proposition. I will keep making the point that the theories deal only with proper subsets of the problems. To stress, in light of the differences between the problems this is not a serious criticism. It is reasonable to think that different problems require different kinds of solutions. My main aim in this section is just to elucidate the different problems.

There are different Fregean claims which need to be distinguished. It will be useful to consider them separately. Take first Frege's claim that there is a fundamental distinction between objects, which are what can serve as referents of singular terms, andconcepts, which are what can serve as referents of (first- and higher-level) predicates. Objects are 'saturated' and concepts 'unsaturated'. This is often discussed as a purported solution to the problem of the unity of the proposition. The criticisms of this idea of Frege's typically found in the literature tend to focus on either the concept horse problem, which is held to show the idea to be untenable, or on how unsatisfactory Frege's-metaphorical—explanation of the difference between concepts and objects is.

But regardless of how unsatisfactory Frege's explanation of the difference is, one can still evaluate the suggestion that there is some fundamental distinction between the referents of singular terms and the referents of predicates. In particular, one can still find oneself led to the conclusion that there undeniably must be some such distinction. And serious though the concept horse problem is, it may be instructive to set it aside and see what Frege's account promises to give us. For the discussions in the literature, although critical, tend to suggest that if Frege's concept/object distinction were tenable then it would solve the problems relating to the unity of the proposition. ${ }^{28}$

\footnotetext{
26 Liebesman (2015, p. 553).

27 Ibid.

28 Gaskin (1995, p. 162f), appears to think that Frege's doctrine, involving the idea that concepts and objects are, as Frege himself puts it, made for each other, would solve the problem if acceptable. But he thinks the concept horse problem refutes the doctrine. Linsky (1992, p. 247f), also gives voice to this view. King (2007, p. 18f), criticizes Frege's saturatedness/unsaturatedness distinction as being unsatisfactorily explained, and moreover thinks arguments to the effect that names do not have senses poses a problem for the Fregean line. But even if Frege's distinction is not satisfactorily explained, it could be reasonable to hold that there must be some such distinction. And arguments to the effect that names don't have senses, while obviously in tension with parts of Frege's view, seem orthogonal to the claim that a Fregean concept/object distinction must be drawn. Vallicella (2000, p. 242f), makes the point I am concerned to make: other concerns aside, Frege's account still fails to solve many problems raised.
} 
Frege not only proposed a concept/object distinction but also repudiated facts and Russellian propositions with entities at the level of reference as constituents. In order clearly to separate appeal to Frege's concept/object distinction from other Fregean theses, I will first consider thehybrid view — certainly not held by Frege - that propositions are Russellian in the sense just characterized but consist of something like Fregean concepts and objects—-some entities that cannot serve as referents of singular terms and some entities that can only so serve. I will further abstract away from Frege's specific claims regarding the nature of concepts. (One might, of course, reasonably hold that Frege's specific view on concepts as functions rules out that there should be complexes built up from concepts and objects. But the general claims, that there is a certain type of entity such that entities of this type can only be the referents of predicates and that predicates can only have referents of this type, do not rule out the existence of such complexes. ${ }^{29}$ )

This hybrid view can seem tailor-made to deal with Combinability. Moreover, it may be argued to help with Unity: these complex entities can exist because the constituents, the unsaturated concepts and the saturated objects, fit each other. However, in the case of Unity, the distinction between the question of the unity of the proposition and the unity of the fact may be relevant. Some who take the unity of the fact to be a serious problem do so because the existence of the entities that are the purported constituents of the fact is not sufficient for the fact to obtain. ${ }^{30}$ The concept/object distinction does not help with this problem. ${ }^{31}$ In general, the distinction does not help with any of the problems specifically pertaining to facts.

Frege's concept/object distinction does not help with Difference: if there is both a proposition and a fact made up of the objects John and Mary and the concept loving, merely saying that there is a concept/object distinction does not help distinguish between them. And clearly it does not help with Representation. (Again to stress: of course, Frege himself did not have in his ontology entities like facts, or other fact-like entities built up from concepts and objects. The point about the unhelpfulness of the concept/object distinction is still important.)

Frege's concept/object distinction can seem to deal with Order. It can seem that it is because the concept that 'loves' stands for is doubly unsaturated and has two different gaps, as it were, that the proposition that John loves Mary is different from the proposition that Mary loves John. In one proposition, John goes into the lovergap and Mary goes into the lovee-gap; in the other, their roles are switched. But that reasoning is a bit quick. If a proposition's nature is fully determined by what its constituents are, then we still have not distinguished the two propositions. All we have in both cases are John, Mary, and Loves, with its two gaps. I will return to this in the next section.

So far the only distinctly Fregean view I have taken into account is that there is some sort of concept/object distinction. Frege of course held other specific views and it might be held that those other views help Frege deal with the unity of the proposition.

\footnotetext{
29 For Frege himself, of course, concepts are functions, and one may well think that functions and arguments should not be seen as constituents of the values of the function.

30 See e.g. Orilia (2007).

31 MacBride (2005, p. 605), stresses this same point.
} 
Let me first discuss in turn appeal to senses; then I will turn to the context principle and the idea that Fregean concepts do not enjoy independent existence.

First, senses. Frege of course believed in senses, and took propositions (or 'Thoughts') to be built up out of senses. And just as he believed in a fundamental distinction between concepts and objects at the level of reference, he believed in a fundamental distinction between saturated and unsaturated senses. ${ }^{32}$ Let us now consider this view on propositions.

If propositions consist of senses, there is a natural way to distinguish between the proposition that $\mathrm{p}$ and the fact that $\mathrm{p}$, for facts are not naturally taken to consist of senses. Difference is then taken care of, but Generalized Difference remains. But the problem of Order is obviously still not dealt with. One might be inclined to say that Frege's appeal to senses helps also with Representation. The supposed reason would be that senses are in and of themselves representational entities. But all we are doing when appealing to senses to explain how propositions are representational is to insist that they are built up from entities which are themselves representational. We do not explain how there can be these representational entities in the first place. Lastly, appeal to senses only promises to help with problems specifically about propositions; problems specifically relating to facts simply are not dealt with.

Sometimes it is said that through his adherence to the context principle-only in the context of a sentence does a word have a meaning - which has been taken to claim that propositions are somehow primary, Frege avoids the unity problems. ${ }^{33}$ The idea would be that given the context principle, the proposition is prior to its parts and so questions about how the proposition is built up from its parts are avoided. Connected to this is the idea that Fregean concepts do not enjoy independent existence. ${ }^{34}$

Full discussion of this would take us too far afield. But distinguishing between the different unity problems is relevant here too. The proposed account does not immediately help with Difference and Representation. ${ }^{35}$ Unity is the problem most clearly dealt with. If a proposition is not dependent on its constituents but it rather is the other way around then questions of how the constituents can combine to constitute the

\footnotetext{
32 Frege argues for both doctrines in tandem. In principle, the case for one doctrine could be good without the other one being so. For example: Frege himself carefully distinguishes senses from any sort of mental entities. But suppose we did take senses to be something like what Frege calls 'ideas'. Ideas would seem to be, in Frege's terminology, objects, and even if properties and relations-Fregean concepts - are unsaturated, the idea of a property or relation might still fail to be.

It is sometimes suggested that Frege took senses to be accurately describable as unsaturated only as proxy: that a sense can be properly called unsaturated exactly when the reference it stands for is unsaturated. Let me not get into potentially contentious matters of Frege interpretation. (But Frege (1892) does say, "not all parts of a thought can be complete; at least one must be 'unsaturated', or predicative; otherwise they would not hold together" (p. 193; my emphasis).) There is still a reason to focus on the possibility of unsaturated senses in the main text. If Frege didn't believe in unsaturated senses, there are no complex entities he believed in such that they are composed of saturated and unsaturated constituents.

33 See e.g. Linsky (1992, p. 266f) and Textor (2009, p. 63fn6). Of course it can be contested what the proper understanding of the context principle is.

34 Consider e.g. Frege's 1882 letter to Anton Marty, where he says, "I think of a concept as having arisen by decomposition from a judgeable content"; quoted in Currie (1984, p. 333).

35 That appeal to the context principle does not help with Generalized Difference is a point Gaskin (2010, p. 303), makes in response to Vallicella (2010).
} 
proposition can be thought to drop out. But Order remains: even given the view under consideration, one can ask what differentiates propositions with the same constituents. It is harder to assess what happens with Combinability. However, it may be thought that Combinability is an issue only if the constituents have an in some sense independent nature which explains how they can combine with other entities to form propositions. If this is right, then the problem of Combinability does not arise given the view we are now considering.

As another illustration of the differences between the unity problems, consider King's work on the unity of the proposition. In his (2007—and see too (2009), (2013) and his contributions to (2014) - King presents a response to the problem of the unity of the proposition according to which propositions are facts. But the proposition that John loves Mary is not, absurdly, identified with the fact that John loves Mary: instead, it is identified with the fact that representations of John, loving, and Mary are suitably related. King ably defends his identification of propositions with these facts against objections. But seen in the bigger context of the cluster of problems related to that of the unity of the proposition, his account can still seem strange: for the same problems that arise with respect to propositions arise with respect to facts, and then reducing propositions to facts does not amount to much of an advance. ${ }^{36}$ The problem of Difference, of how the proposition that $\mathrm{P}$ is distinct from the fact that $\mathrm{P}$, is of course neatly dealt with by King's account: while King holds that propositions are facts but identifies them with other facts. But a variant of Order remains: how, in general, is the fact that a Rs b distinct from the fact that $\mathrm{b}$ Rs a? When it comes to Combinability, King does not even attempt to deal with the issue of why some entities but not others can be combined so as to form facts. As for Unity, King reduces the problem of how there can be such complexes as propositions to the problem of how there can be such complexes as facts. This is progress if, but only if, the unity problem for facts is easier to deal with than that for propositions. But the problems are exactly parallel.

When it comes to Representation, King (see especially King (2009)) rejects the view that propositions "by their very natures and independently of all minds and languages" represent the world. ${ }^{37}$ Instead he proposes a view on which "it is something we speakers of languages do that results in propositions representing things as being a certain way and so having truth conditions". 38 This means that King in effect rejects a presupposition of the problem of Representation.

\section{The resolution of the unity problems}

Let us now turn to the questions of what lessons one can draw concerning the unity problems based on what has been said about the regress problems. The main lesson of the discussion of the constitution regress and the proposition regress was that facts and propositions are not fully determined by the existence of the entities that are

\footnotetext{
36 King remarks on this in his (2013), saying that it still is progress to turn two problems into one.

37 King (2009, p. 259).

38 King (2009, p. 261).
} 
constituents of them; it also matters how the constituents are related. I will here apply this lesson to the unity problems, and see to what extent this helps deal with them.

The two problems most immediately dealt with are (Generalized) Difference and Order. Both problems are immediately worrisome insofar as propositions and facts are completely determined by what their constituents are. But once we add, with the solution to the constitution regress that has just been presented, that there is a relating relation (in Russell's phrase) — the constituents are related by a relation, and the relation's so relating the constituents is a matter different from it itself being a constituent of the proposition-one can deal with Generalized Difference by saying that even if two complex entities have the same constituents, they are different by virtue of different relating relations. Compare the proposition that John loves Mary with the fact that John loves Mary. They may contain the same constituents, but the proposition is one where John is represented as loving Mary; the fact is one where John instantiates loving Mary. The constituents are the same; the relation is different. (Or compare for that matter the set $\{$ John, love, Mary $\}$, or the mereological sum of these things, if they do have a sum.)

As for Order, once we add that there is a relating relation, we can say e.g. it comes to the fact that $\mathrm{aRb}$, distinct from $\mathrm{bRa}$, the instantiation relation relates $\mathrm{a}, \mathrm{R}$, and $\mathrm{b}$ in that order. Just like the relation of loving distinguishes between the lover and the lovee, the instantiation relation distinguishes between its arguments. This may sound unimpressive as a response to Order. Someone intent on pressing the problem may be inclined to say: but what makes it the case that one entity goes into one argument place of the relation and the other entity goes into another? But at some point explanations come to an end. What sort of account might even count as a satisfactory explanation of this sort of thing? Compare: if it is supposed that John loves Mary, and you wonder why John goes into one argument place of the loving relation and Mary another, why should this be supposed to be a reasonable thing to wonder? What sort of answer might satisfy, if the straightforward answer that John is the lover and Mary is the lovee doesn't?

In the previous section. I discussed whether a Fregean distinction between concepts and objects helps solve the problem of Order. It may seem that it does: if the concept loves has two gaps, then in the proposition or fact that John loves Mary, John is in one gap and Mary is in another while in the proposition or fact that Mary loves John the reverse holds. But as against this I insisted that even given Frege's doctrine all we have, in both cases, are John, Mary, and loves with its two gaps. I can now elaborate on the earlier complaint. If one holds that the nature of a proposition or fact is fully determined by what entities it contains as constituents, my earlier complaint stands. What the Fregean needs is that John, Mary and loves stand in the right relation: that John and Mary are in the gaps they are in. For that one also needs what I have been stressing: the rejection of existentialism.

When it comes to Combinability, the solution to the fact and proposition regresses suggests the following answer: only such-and-such collections of entities can combine into facts, for only such-and-such collections of entities can be the arguments of the relating relations. There is the residual feeling that there is more to be said. One may want to ask: why can this or that relating relation serve to relate these entities but not those? But while there is that further question to be asked, any foundational worry 
about the possibility of the existence of propositions or facts based on Combinability is answered already by the schematic remarks given here.

What about Unity? A facile answer to the Unity problem, based on the previous considerations, is to say that what accounts for the constituents being combined into the unity they are is how they are related. What would the remaining worry be? Russell thought there was a reason for concern about the existence of complexes different from mere aggregates or collections. But from a contemporary perspective it is unclear why these cases should be treated differently in the first place. Why is it supposed to be more problematic to hold that there is a complex entity, a fact, which obtains when the constituent entities stand in the instantiation relation, than it is to hold that there is another type of complex entity, an aggregate, which exists when the constituent entities stand in the parthood relation to the whole, or to hold that there is a set which exists when the constituent entities stand in the membership relation? A difference between the fact case and these other two cases is of course that in the latter two cases, the complex entity necessarily exists if the constituents do. But in this respect, propositions group with aggregates and sets and not with facts.

Suppose then that the worry is the completely general one: how can there be complex entities at all, whether aggregates or facts or propositions? There is a question of why this should be a reasonable worry in the first place. One historically important reason is provided by Bradley: the existence of complex entities demands that their constituents be related, but relatedness is impossible. I dealt with the regress problems above, but acknowledged that what I have to say is not designed to move someone who is resolutely skeptical about relatedness.

When it comes to Representation, one must distinguish between different problems. The more general one is that of how mind- and language-independent representationality is possible in the first place, and the present remarks do not do anything to address that problem. Another is how an entity whose only constituents are John, loves and Mary-themselves non-representational, could be true or false, and when it comes to this problem, saying that the nature of the entity is not fully determined by the existence of its constituents is relevant. If in the proposition the constituents, John, loves and Mary are related by the represented as instantiating-relation, that goes some way toward explaining how the proposition could be true, even if the mere collection of items John, loving and Mary cannot be true. Specifically, it goes some way toward explaining why it is true if John and Mary, in that order, instantiate the loving-relation. Even though, again, this explanation does not go any way towards responding to the general skepticism just mentioned.

\section{Russell}

As earlier stressed, there are similarities between the positive picture I have sketched and what Russell proposed in (1903/96). Russell's way out of the regress, like mine, involves denying existentialism, and it involves taking relatedness as primitive. It is, in Russell's terms, the relation actually relating that does the theoretical work.

Some commentators have been sharply critical of Russell's way of dealing with the unity problem. Davidson (2005) says, "Russell continued to insist on the reality 
of relations despite the fact that he could not give a consistent account of the relations which unify a proposition" 39 . And Peter Hylton (1990) says,

Russell takes an extreme realist view both of the things which can be the constituents of propositions-Socrates, wisdom, etc.-and of the propositions themselves-Socrates is wise, for example. Now in a case of this sort, the proposition is clearly made up from the entities in some way; but in what way? How do the entities combine to form the proposition? Russell admits that he has no answer to this question; but in fact the situation is worse than he suggests. The problem is in principle unsolvable within the metaphysical framework which he establishes. $^{40}$

The "metaphysical framework" is one that Hylton describes as a "one category" framework. For Russell, every entity can serve as the logical subject of a propositionroughly, be what a proposition is about — and anything that can so serve Russell calls a "term". When Hylton says that Russell has only one ontological category, this is what he means. Frege's ontology is not a one category ontology in Hylton's sense. As I stressed earlier, appeal to Frege's categories does not get around the unity problem.

What Russell does offer, quite clearly, is a view on which the constituents of a proposition are unified into a proposition, even if he, by his own lights, cannot give any sort of informative account of how that is so. As he says, "The verb, when used as a verb, embodies the unity of a proposition and is thus distinguishable from the verb considered as a term, though I do not know how to give a clear account of the precise nature of the distinction". Even if Russell couldn't say anything informative, he is not doomed to inconsistency, contrary to what Davidson appears to indicate. Not being able to give a consistent yet informative account is not the same as being doomed to inconsistency. Nor does any of this mean that the problem is unsolvable for Russell. Saying that one cannot give an informative answer to a question is not immediately to admit defeat.

One reason why Russell (1903/96) theory of propositions is in ill repute is that he did not distinguish between propositions and facts. The entity that is John's loving Mary exists whether or not John loves Mary; it is only that if John does not love Mary it is false. But this further commitment of Russell's is independent of the more fundamental idea that relations can contribute to the obtaining of facts in different ways, as mere constituents or as relations actually relating.

There may however be a reason why, given Russell's own philosophical aims, the sort of account Russell gives (and that I give) may be unsatisfactory. Russell set out to oppose the monism of the British idealists, according to which the world as a whole is more fundamental than its parts. One way he could have done so would have been to take individual propositions or facts as fundamental. But he set out to reductively explain propositions and facts in terms of constituents. And appeal to relations actually relating is in some tension with this aim, for speaking of relations actually relating seems to be to speak of entities being related to each other. And one

\footnotetext{
39 Davidson (2005, p. 106).

40 Hylton (1984, p. 381). It is not obvious to me what Hylton means by "extreme" in the context.
} 
can easily envisage the objection: if Russell helps himself to, say, a's being R-related to $b$, how is that substantively different from his helping himself to the fact that a bears $\mathrm{R}$ to $\mathrm{b}$ ? From some points of view, there may be a significant step there: the talk of facts is ontologically committing in a way that mere talk of entities being related is not. But Russell was, at the time, ontologically easy-going. And if some sort of reductive account of the world and the entities in there being related was what was being sought, appeal to a primitive notion of relations relating is not of great help.

\section{Concluding remarks}

I have distinguished the constitution regress from other, less theoretically interesting regress arguments, and defended a solution to the constitution regress, one that involves rejecting the existence-only assumption and the constituency assumption. The regress arguments discussed here are often brought up together with the problem of unity of the proposition. One must distinguish between different unity problems. Some such problems should not be taken as serious. And the unity problems worth taking seriously are disparate, and it is only to be expected that different problems in the general theoretical vicinity receive different solutions. That is also what we saw when discussing the consequences of the present solution to the constitution regress for these unity problems.

Acknowledgements This paper has existed in draft form for quite some time now. I wish to thank audiences at University of Nevada-Las Vegas, Stockholm University, the Midwest Annual Workshop in Metaphysics at University of Notre Dame, Grupo de Acción Filosófica in Buenos Aires, as well as students in classes taught at Cornell University and Uppsala University, and David Kovacs, David Liebesman, Eric Rowe, Henrik Rydéhn and two anonymous referees for helpful feedback. Some of the research on this has been supported by a generous grant from Riksbankens Jubileumsfond, for the project The Lightness of Being.

Open Access This article is distributed under the terms of the Creative Commons Attribution 4.0 International License (http://creativecommons.org/licenses/by/4.0/), which permits unrestricted use, distribution, and reproduction in any medium, provided you give appropriate credit to the original author(s) and the source, provide a link to the Creative Commons license, and indicate if changes were made.

\section{References}

Armstrong, D. M. (1989). Universals: an opinionated introduction. Boulder, Colorado: Westview Press. Bradley, F. H. (1893). Appearance and reality. London: Swan Sonnenschein.

Burge, T. (2007). Predication and Truth. Journal of Philosophy, 104, 580-608.

Candlish, S. (1996). The unity of the proposition and Russell's theories of judgment. In R. Monk \& A. Palmer (Eds.), Bertrand Russell and the origins of analytical philosophy (pp. 103-133). Bristol: Thoemmes Press.

Candlish, S. (2007). The Russell-Bradley dispute and its significance for twentieth-century philosophy. New York: Palgrave MacMillan.

Candlish, S., \& Damnjanovic, N. (2012). The tractatus and the unity of the proposition. In J. Zalabardo (Ed.), Wittgenstein's early philosophy (pp. 64-98). Oxford: Oxford University Press.

Collins, J. (2011). The unity of linguistic meaning. Oxford: Oxford University Press.

Currie, G. (1984). Frege's metaphysical argument. Philosophical Quarterly, 34, 42-329.

Davidson, D. (2005). Truth and predication. Cambridge, Massachusetts: Harvard University Press.

Della Rocca, M. (2013). The taming of philosophy. In Mogens Lærke, J. E. H. Smith, \& Eric Schliesser (Eds.), Philosophy and its history. New York: Oxford University Press. 
Fine, K. (2000). Neutral relations. Philosophical Review, 109, 1-33.

Frege, G. (1892). On concept and object. Vierteljahresschrift für wissenschaftliche Philosophie, 16, 192-205.

Gaskin, R. (1995). Bradley's regress, the copula, and the unity of the proposition. Philosophical Quarterly, $45,80-161$.

Gaskin, R. (2008). The unity of the proposition. Oxford: Oxford University Press.

Gaskin, R. (2010). The unity of the proposition: Replies to Vallicella, Schnieder, and García-Carpintero. Dialectica, 64, 11-303.

Hanks, P. (2015). Propositional content. Oxford: Oxford University Press.

Hylton, P. (1990). Russell, idealism, and the emergence of analytic philosophy. Oxford: Oxford University Press.

Hylton, P. (1984). The nature of the proposition and the revolt against idealism. In R. Richard, J. B. Schneewind, \& Q. Skinner (Eds.), Philosophy in history: Essays on the historiography of philosophy (pp. 97-375). New York: Cambridge University Press.

King, J. (2007). The nature and structure of content. New York: Oxford University Press.

King, J. (2009). Questions of unity. Proceedings of the Aristotelian Society, 109, 77-257.

King, J. (2013). Propositional unity: What's the problem, who has it and who solves it? Philosophical Studies, 165, 71-93.

King, J., Soames, S., \& Speaks, J. (2014). New thinking about propositions. Oxford: Oxford University Press.

Lewis, D. (1983). New work for a theory of universals. Australasian Journal of Philosophy, 61, 77-343.

Lewis, D. (1992). Armstrong on combinatorial possibility. Australasian Journal of Philosophy, 70, 211-224.

Lewis, D. (2002). Tensing the copula. Mind, 111, 1-13.

Liebesman, D. (2015). Predication as ascription. Mind, 124, 69-517.

Linsky, L. (1992). The unity of the proposition. Journal of the History of Philosophy, 30, 73-243.

MacBride, F. (2005). Review: Herbert Hochberg, introducing analytic philosophy: Its sense and nonsense 1879-2002. Dialectica, 59, 7-81.

MacBride, F. (2005a). The particular-universal distinction: A dogma of metaphysics? Mind, 114, 565-614.

Macbride, F. (2014). Review: The unity of the proposition, by Richard Gaskin. Mind, 123, 898-901.

Maurin, A.-S. (2012). Bradley's regress. Philosophy Compass, 7, 794-807.

Orilia, F. (1991). Type-free property theory, Bradley's regress, and Meinong and Russell reconciled. Grazer Philosophische Studien, 39, 25-103.

Orilia, F. (2007). Bradley's regress: Meinong versus Bergmann. In L. Addis, G. Jesson, \& E. Tegtmeier (Eds.), Ontology and analysis (pp. 63-133). Frankfurt: Ontos Verlag.

Peacock, H. (2011). Is there a problem about propositional unity? Dialectica, 65, 393-418.

Russell, B. (1903/96). The principles of mathematics. New York: W. W. Norton.

Sainsbury, M. (1996). How can we say something? In R. Monk \& A. Palmer (Eds.), Bertrand Russell and the origins of analytical philosophy (pp. 137-153). Bristol: Thoemmes.

Soames, S. (2010). What is meaning?. Princeton: Princeton University Press.

Soames, S. (2014). Why the traditional conceptions of propositions can't be correct. In J. C. King, S. Soames, \& J. Speaks (Eds.), New thinking about propositions (pp. 25-45). Oxford: Oxford University Press.

Textor, M. (2009). Unsaturatedness: Wittgenstein's challenge Frege's answer, Proceedings of the Aristotelian Society, 109, 62-82.

Vallicella, W. (2000). Three conceptions of states of affairs. Noûs, 34, 59-237.

Vallicella, W. (2010). Gaskin on the unity of the proposition. Dialectica, 64, 77-265.

Williamson, T. (1985). Converse relations. Philosophical Review, 94, 62-249.

Wittgenstein, L. (1922). Tractatus logico-philosophicus (C. K. Ogden, Trans.). London: Routledge \& Kegan Paul.

Wright, C. (1998). Why Frege does not deserve his grain of salt. Grazer Philosophische Studien, 55, 63-239. 